\title{
The Effect of Low-Level Laser Therapy and Curcumin on the Expression of LC3, ATG10 and BAX/BCL2 Ratio in PC12 Cells Induced by 6-Hydroxide Dopamine
}

\author{
Fatemeh Sadat Tabatabaei Mirakabad', Maryam Sadat Khoramgah', ${ }^{1,2}$, Foozhan Tahmasebinia ${ }^{3}$, Shahram \\ Darabi $^{4}$, Saeed Abdi ${ }^{5}$, Hojjat Allah Abbaszadeh ${ }^{1 *}$, Shahrokh Khoshsirat ${ }^{2 *}$ \\ 'Laser Application in Medical Sciences Research Center, Shahid Beheshti University of Medical Sciences, Tehran, Iran \\ ${ }^{2}$ Hearing Disorders Research Center, Shahid Beheshti University of Medical Sciences, Tehran, Iran \\ ${ }^{3}$ Proteomics Research Center, Faculty of Paramedical Science, Shahid Beheshti University of Medical Sciences, Tehran, Iran \\ ${ }^{4}$ Cellular and Molecular Research Center, Qazvin University of Medical Science, Qazvin, Iran \\ ${ }^{5}$ Gastroenterology and Liver Diseases Research Center, Research Institute for Gastroenterology and Liver Diseases, Tehran, Iran
}

\section{*Correspondence to \\ Hojjat-Allah Abbaszadeh, Laser Application in Medical Sciences Research Center and Department of Biology and Anatomical \\ Sciences, school of medicine, Shahid Beheshti University of Medical Sciences, Tehran, Iran P.O.Box: 19395-4719. \\ Email: \\ Dr.abbaszadeh@sbmu.ac.ir; Shahrokh Khoshsirat, Hearing disorders research center, Shahid Beheshti University of Medical Sciences, Tehran, Iran}

Published online June 21, 2020

\section{Introduction}

Parkinson's disease (PD) is a neurodegenerative movement disorder characterized by bradykinesia, muscular rigidity, and tremor. In the pathogenicity of $\mathrm{PD}$, genetic and environmental factors play an important role. ${ }^{1}$ The precise molecular mechanisms underlying PD remain to be completely elucidated. The impaired redox signaling, mitochondrial dysfunction, excitotoxicity, chronic inflammation, early apoptosis, and synaptic loss in dopaminergic neurons are several factors that are associated with PD pathogenicity. ${ }^{2}$ Based on recent evidence, stress-mediated neuroinflammation in the brain is evident. ${ }^{3}$ Reactive oxygen species (ROS) could be generated through different mechanisms such as dopamine metabolism, NADPH oxidases, Fenton reaction, and aging, and they are associated with the pathogenicity of neurodegenerative disorders. ${ }^{4}$ Thus, the prevention of oxidative stress could be considered as a potential therapeutic strategy. After treating nervegrowth-factor-differentiated PC12 cells with neurotoxins 6-hydroxydopamine (6-OHDA), neurons take up 6-OHDA which causes damage due to mitochondrial dysfunction, resulting in over-production of ROS and DNA damage., ${ }^{5,6}$ Curcumin $(\mathrm{CU})$ is a polyphenol compound and a major component of the Curcuma longa plant. Due to the inhibition of cyclooxygenase-2, lipoxygenase, and inducible nitric oxide synthase by $\mathrm{CU}$, it has anti-inflammatory and antioxidant activities. ${ }^{7-9} \mathrm{CU}$

Please cite this article as follows: Tabatabaei Mirakabad FS, Khoramgah MS, Tahmasebinia F, Darabi S, Hojjat Allah Abbaszadeh HA, Khoshsirat S. The effect of low-level laser therapy and curcumin on the expression of LC3, ATG10 and BAX/BCL2 ratio in PC12 cells induced by 6-hydroxide dopamine. J Lasers Med Sci. 2020;11(3):299-304. doi:10.34172/jlms.2020.50. 
can reduce the level of lipid peroxidation and regulate antioxidant enzymes. ${ }^{10-12}$ Photobiomodulation or lowlevel laser therapy (LLLT) improves electron transport in mitochondria and increases mitochondrial membrane potential and it also induces the production of low levels of ROS in the normal cell. ${ }^{13,14}$ In the present study, we provide evidence that CU and LLLT inhibit ROS production and apoptosis in PC12 cells treated with 6-OHDA.

\section{Materials and Methods \\ Cell Culture}

PC12 cells were cultured and seeded in a DMEM/F12/ NGF medium which was supplemented by (penicillin -streptomycin) $100 \mathrm{U} / \mathrm{mL}$ ), 5\% fetal bovine serum and $5 \%$ horse serum using poly-L-lysine coated T-75 culture flasks. A humidified incubator with $5 \% \mathrm{CO}_{2}$ was used to incubate cells at $37^{\circ} \mathrm{C}$. The cells between passages 2 and 8 were used for this experiment because of the easiness in their isolation. After passage 10, all cells got clumpy and the isolation was difficult. A cell scraper was used to dislodge cultured cells from the flask after $80 \%$ confluency. Then the poly-L-lysine coated 96-well microplate was used to grow these cells at a density of $1 \times$ $10^{5}$ cells $/ \mathrm{mL}$. After overnight incubation, the cells adhered to the substrate. Then all cells were treated with $100 \mu \mathrm{M}$ concentrations of 6-OHDA for 24 hours. The cells in the negative control group were only cultured in DMEM/F12 Cell Culture Media and the cells in the positive control group were exposed only to 6-OHDA.

\section{Application of CU}

DMSO was used to prepare the CU stock solution (50 mM). CU was diluted before adding to cell culture because the final concentration of DMSO should be kept at $1 \%$ in the culture medium. One hour after seeding, $\mathrm{CU}$ was added to the cell culture medium in different concentrations of $1.0,2.5,5.0,7.5$, and $10.0 \mu \mathrm{M}$.

\section{PC12-6-OHDA Treatment}

The PC12 cells were cultured in DMEM/F12/NGF 5\% FBS, PC, and SP (1\%). Afterward, these cells were exposed to CU and LLLT (LLL Protocol: $0.0022 \mathrm{~W} / \mathrm{cm}^{2}, 635 \mathrm{~nm}, 4$, $6,8 \mathrm{~mW}, 1.5 \mathrm{~J} / \mathrm{cm}^{2}$ ). The laser beam diameter was $1.56 \mathrm{~cm}$, and the laser beam surface area was $1.96 \mathrm{~cm}^{2} .13,14$

\footnotetext{
Determination of Cell Viability

In order to investigate the cytotoxicity effect of $\mathrm{CU}$ treatment on 6-OHDA induced PC12, 3-(4, 5-dimethylthiazol-2-yl)-2,5-diphenyltetrazolium bromide (MTT) assay was used. MTT reagent, a yellow tetrazole, is converted to insoluble purple formazan after reducing in the mitochondria of living cells. The resultant shift in color was measured by absorbance microplate readers at $570 \mathrm{~nm}$. The cell viability mean percentage of each group was compared with the untreated control mean percentage and they were reported as mean \pm
}

standard error of the mean (SEM).

\section{Examination of PC12 Cell Morphology}

The 6-well plates were used for seeding the PC12 cell. Fifty cells were selected on a random basis and they were examined in each group. The Cell A program was used to analyze the findings. Afterward, images were taken randomly from each well (20 images per well) for morphological analysis purposes. The cell body area and neurite length were measured after the administration of LLLT and CU. The neurite length was considered the sum of the lengths of all primary branches plus associated twigs. The cell body area was considered as the area of a cell body without its branches. The minimum number of quantified cells per treatment was 50 .

\section{Real-Time PCR}

To quantify the transcripts of genes including ATG10, $\mathrm{Bax}, \mathrm{Bcl} 2$, and LC3, the total RNA of these cells from the dissected spine was extracted using the RNA Extraction kit in the first week (Invitrogen, USA). The Prime Script TM RT reagent Kit (Fermentas, Lithuania) was used to produce cDNAs. Syber Green PCR Master Mix (Applied Biosystems, USA) was used for performing reverse transcription using Step OnePlus ${ }^{\mathrm{Tm}}$ Real-Time PCR System (Applied Biosystems, USA) based on the protocols provided by the company. Initial denaturation was carried out at $95^{\circ} \mathrm{C}$, for 30 seconds, annealing at $56^{\circ} \mathrm{C}$ for 45 seconds, extension at $72^{\circ} \mathrm{C}$ for the duration of 45 seconds and a final polymerization at $65^{\circ} \mathrm{C}$ for 10 minutes. The forward and reverse primer sequences for bax, bcl2, and GAPDH genes were briefed in Table 1. For gene target expression analysis $(2 \Delta \Delta \mathrm{Ct})$, a comparative $\mathrm{Ct}$ was applied. GAPDH level was used for normalizing all samples as the loading control.

\section{Data Analysis}

One-way ANOVA and Tukey post hoc test were conducted for statistical analysis. The data were presented as mean \pm SEM and the $P$ value $<0.05$ was considered as statistically significant.

\section{Results}

The Morphological Characteristics of PC12 Cells PostTreatment With LLLT and CU

Based on our morphological findings, cell exposure to 6-OHDA for 24 hours decreased length and width of the neurite which was rescued by the treatment of cells with LLLT and/or CU. An increase in cell body area induced by $6-\mathrm{OHDA}$ were rescued in the group that received $\mathrm{CU}$, LLLT, and CU+LLLT (Figure. 1).

\section{Dose-Response of CU Toxicity}

In order to find the half-maximal inhibitory concentration of $\mathrm{CU}$, different concentrations of $\mathrm{CU}$ were investigated using 10000 cells/well. The cell viability decreased 
Table 1. Primer Sequences Used in the qRT-PCR

\begin{tabular}{|c|c|c|c|c|}
\hline Gene & Primer Type & Sequence & Annealing Temperature & Product Size (Base Pairs) \\
\hline \multirow{2}{*}{ Bax } & $\mathrm{F}$ & CCCGAGAGGTCTTTTTCCGAG & \multirow{2}{*}{65} & \multirow{2}{*}{$210 \mathrm{bp}$} \\
\hline & $\mathrm{R}$ & CCAGCCCATGATGGTTCTGAT & & \\
\hline \multirow{2}{*}{$\mathrm{Bcl} 2$} & $\mathrm{~F}$ & TACAGGCTGGCTCAGGACTAT & \multirow{2}{*}{65} & \multirow{2}{*}{ 230bp } \\
\hline & $\mathrm{R}$ & CGCAACATTTTGTAGCACTCTG & & \\
\hline \multirow{2}{*}{ LC3 } & $\mathrm{F}$ & TGTTAGGCTTGCTCTTTTGG & \multirow{2}{*}{58} & \multirow{2}{*}{$218 \mathrm{bp}$} \\
\hline & $\mathrm{R}$ & GCAGAGGAAATGACCACAGAT & & \\
\hline \multirow{2}{*}{ ATG10 } & $\mathrm{F}$ & ССTGTTTGCTTGGGATAGTGG & \multirow{2}{*}{61} & \multirow{2}{*}{ 198bp } \\
\hline & $\mathrm{R}$ & АСТТССССАТСААТСТССАС & & \\
\hline \multirow{2}{*}{ GAPDH } & $\mathrm{F}$ & ССАСААСТС ТТССАТТСТС & \multirow{2}{*}{59} & \multirow{2}{*}{ 200bp } \\
\hline & $\mathrm{R}$ & CCAAGATTCACGGTAGATAC & & \\
\hline
\end{tabular}

significantly in PC12 cells incubated with an increasing concentration of $\mathrm{CU}$ from 0 to $10 \mu \mathrm{M}$ for 24 hours. It was found that there is an association between increasing CU concentration and increased cell death. By using $10 \mu \mathrm{M}$ of $\mathrm{CU}$, the mortality rate rose dramatically in comparison with the other groups. The survival rate decreased in all groups in comparison with the control group except in the presence of 5.0 micro molar of CU. (Figure 2).

6-OHDA-Induced Cell Death in Different Groups After treating cells with 6-OHDA $100 \mu \mathrm{M}$ for 24 hours, CU, LLLT, and CU+LLLT, the apoptosis rate was evaluated using MTT. The results showed that the presence of 6-OHDA increased cell death and mortality rate dramatically in comparison with the other groups. However, in all three groups, survival was reduced significantly in comparison with the 6-OHDA group (Figure 3).

The Effect of LLLT+CU on the Neuritis Length and Cell Body Area of PC12 Cells After 6-OHDA Treatment

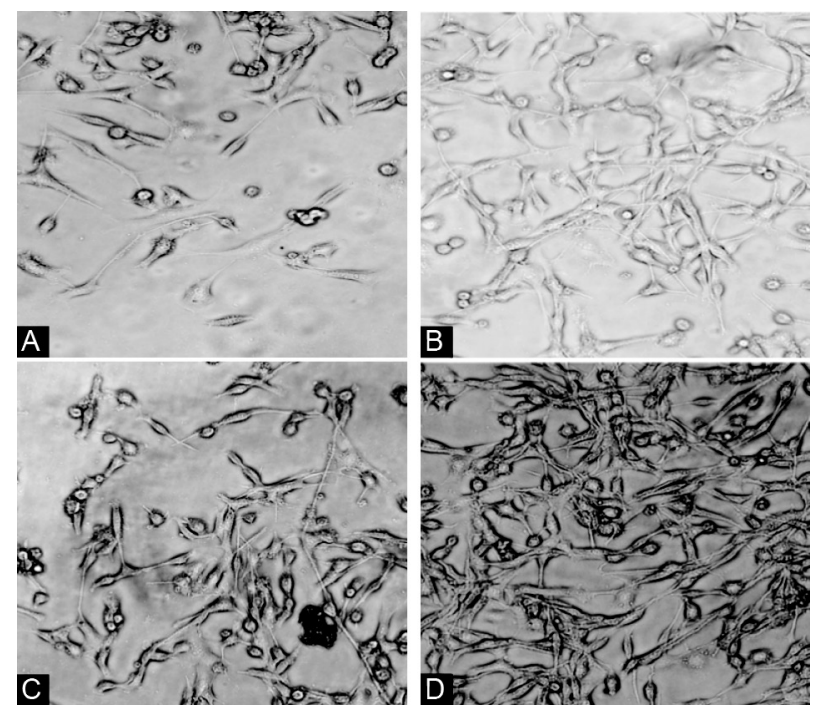

Figure 1. Morphology of PC12 cells after treating by $6 \mathrm{OHDA}(\mathrm{A}), \mathrm{CU}(\mathrm{B})$, $\operatorname{LLLT}(\mathrm{C})$, and LLLT+CU (D).
Based on our findings using the Cell A program, the neuritis length decreased significantly after treating cells with 6-OHDA which is responsible for inducing oxidative stress. The decrease in 6-OHDA group was rescued by CU, LLL, and LLLT+CU treated group. The level of rescue is higher LLLT+CU other two groups (Figures 4 and 5).

Effect of LLLT+CU on the BAX/BCL2 Ratio in 6-OHDATreated Cells

Based on the results of real-time PCR, the $\mathrm{Bax} / \mathrm{Bcl} 2$ ratio increased in the 6-OHDA-treated cells in comparison

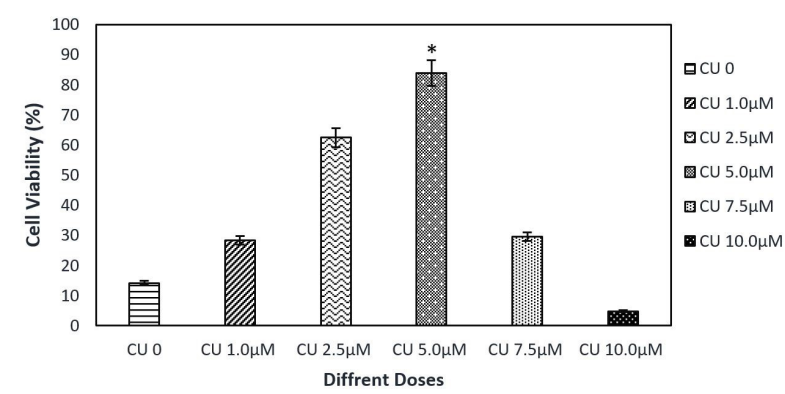

Figure 2. The Effect of Different Doses of CU on Cell Viability. The results indicated that $5 \mu \mathrm{M}$ of $\mathrm{CU}$ was the optimal dose for cell viability.

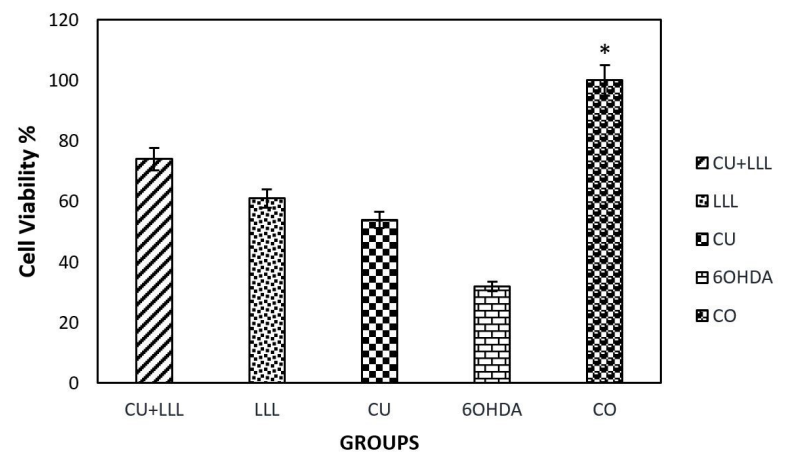

Figure 3. The Effect of 6-OHDA, CU, LLLT, CU+LLLT on Cell Viability. The results indicated that the mortality rates increased after treating by 6-OHDA and decreased after treating by CU, LLLT, and CU+ LLLT $(* P<0.5)$. 
with the control group which was rescued by LLL, CU, $\mathrm{LLL}+\mathrm{CU}$ groups, but the level of rescue is highest in the LLLT+CU-treated group in comparison with the control group (Figure 6).

Effect of LLLT+CU on the LC3 and ATG10 in 6-OHDATreated Cells

The real-time PCR analysis showed that the expression of LC3 and ATG10 decreased in 6-OHDA-treated cells. ATG10 and LC3 are indicators of the accumulation of autophagosomes and the decrease in their expression level in 6-OHDA treated group were rescued significantly by LLLT+CU, LLL and CU treatment (Figure 7).

\section{Discussion}

In this study, we investigated the neuroprotective effects of CU and LLLT on the LC3/ATG10 expression and BAX/BCL2 expression ratio in PC12 Cells induced by 6-OHDA. First, the PC12 cells were treated with 6-OHDA and the viability rate of them was examined using the MTT technique. Due to the apoptosis of PC12 cells, the $\mathrm{Bax} / \mathrm{Bcl} 2$ ratio and LC3/ATG10 expression were measured for evaluating apoptosis and autophagy in different groups by the real-time PCR technique.

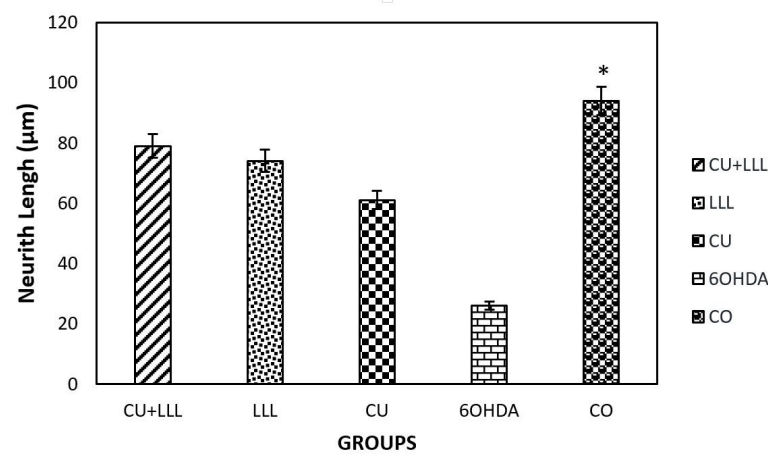

Figure 4. The effect of CU, LLLT, and CU+LLLT on the PC12 Neurith length was defined as the sum of lengths of all primary branches and their associated twigs. ${ }^{*} P<0.05$ significantly different from the $6 \mathrm{OHDA}$ groups

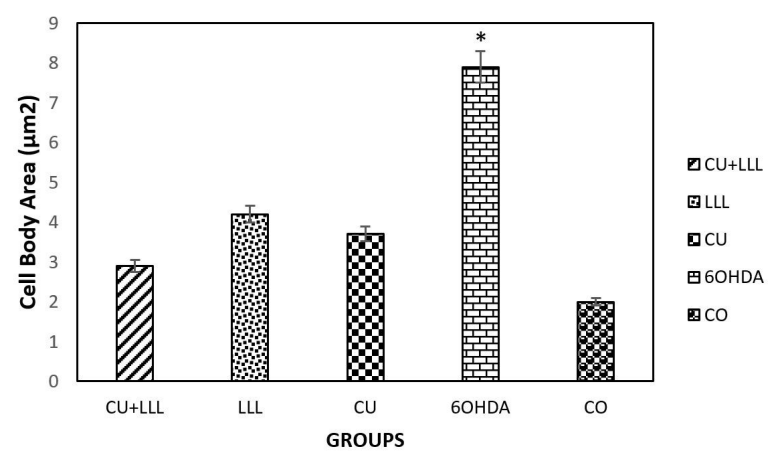

Figure 5. The Effect of CU+LLLT, LLLT, CU, and 6OHDA on the Morphology of PC12 cells. The cell body area was considered without its branches. The cell body area was significantly higher in the $6 \mathrm{OHDA}$ group than the other groups $(* P<0.05)$.
Since cell survival and viability increased in LLLT+CU6-OHDA-treated cells in comparison with the control group. Thus, LLLT+CU significantly decreased the apoptosis rate which was associated with oxidative stress caused by 6-OHDA. Due to the neuroprotective effects of CU and LLLT, the viability of PC12 cells pretreated with 6-OHDA increased significantly. The results of other researchers confirmed our findings. ${ }^{15} \mathrm{PC} 12$ cells were used to exhibit the morphology of the nerve-like cell, due to the high passage capability of PC12 cells and good proliferation and differentiation; they are suitable for the study of physiology and pathology of the nervous system as well as the neurodegenerative disease. ${ }^{16} \mathrm{PC} 12$

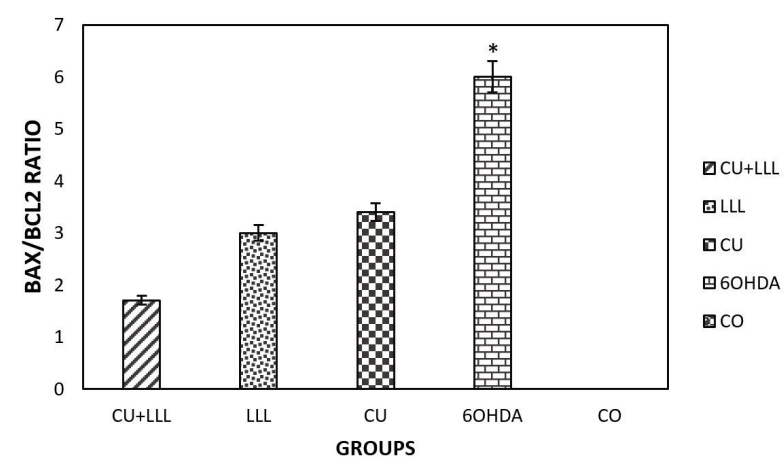

Figure 6. The Bax/Bcl2 Expression Ratio in Different Groups. The results indicated that an increase in the $\mathrm{Bax} / \mathrm{Bcl} 2$ ratio in the $6-\mathrm{OHDA}$ group was significantly rescued by $\mathrm{CU}, \mathrm{LLL}, \mathrm{CU}+\mathrm{LLL}$ groups $(* P<0.05)$.
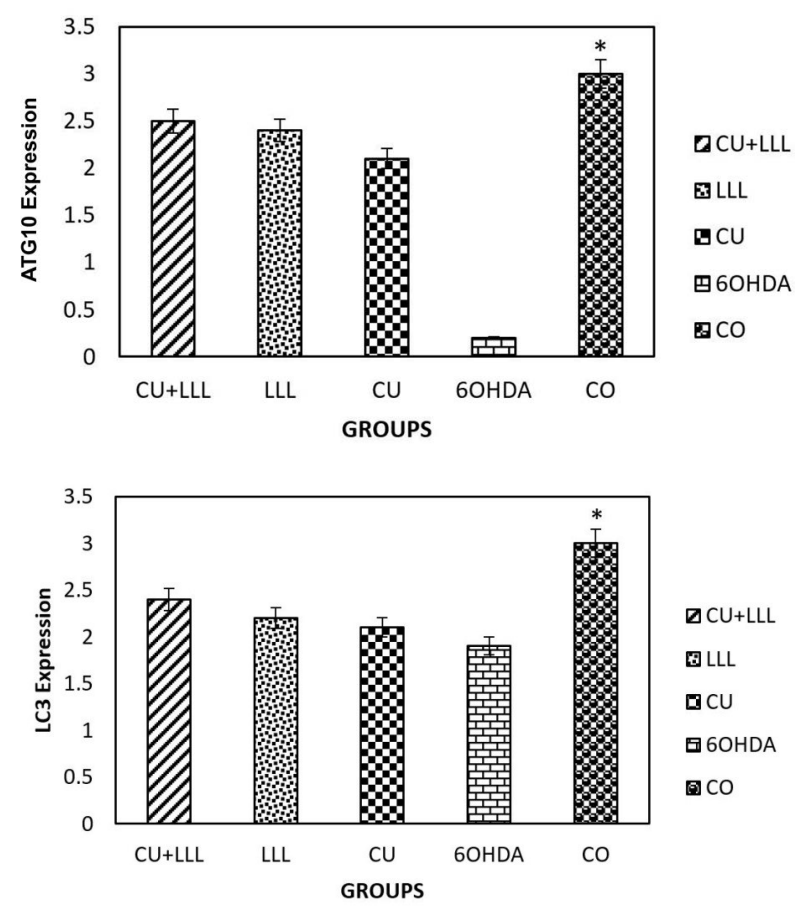

Figure 7. The Expression of LC3 and ATG10 in Different Groups. A decrease in theLC3 and ATG10 expression in the 6-OHDA group was significantly rescued by $\mathrm{CU}, \mathrm{LLL}, \mathrm{CU}+\mathrm{LLL}$ groups $\left({ }^{*} P<0.05\right)$. 
cells have a similar phenotype to sympathetic ganglionic cells so they have been used in hypoxia studies. ${ }^{17}$ Many pieces of evidence have proven that the generation of excessive ROS may induce oxidative stress that may lead to neuroinflammation and neurodegeneration, particularly in Alzheimer's and Parkinson's disorders. ${ }^{18,19}$ In this study, the treatment of cells with increasing concentration of 6-OHDA may increase ROS exceeding the level of antioxidant production in the cells which may result in the oxidative stress of the cell, mitochondrial dysfunction, and neuronal death. ${ }^{20}$ Free radicals generated by 6-OHDA may cause DNA damage, lipid peroxidation, and cytoskeletal disorganization that ultimately trigger neuronal apoptosis. ${ }^{21}$ Flavonoid polyphenols, particularly $\mathrm{CU}$, have been proposed as a potential candidate for protecting dopaminergic neurons against ROS. ${ }^{22}$ In this study, the neuroprotective effect of CU on 6-OHDAInduced neurotoxicity in PC12 cells was investigated, which could be considered as a cellular model of PD. It was shown that the combination of LLLT and CU may have a protective role for PC12 cells against 6-OHDA. The pretreatment of PC12 cells with $5 \mu \mathrm{M}$ CU showed an increase in cell viability. In fact, pretreating PC12 cells with CU may result in an increase in antioxidant enzymatic activity ${ }^{23}$ that functions in eliminating ROS before inducing cellular damage. ${ }^{24}$

\section{Conclusion}

The combination of LLLT and CU has a neuroprotective effect on PC12 cells against 6-OHDA-induced neurotoxicity. Due to an increase cell viability and decrease an increase in the $\mathrm{Bax} / \mathrm{Bcl} 2$ ratio which shows cell susceptibility to apoptosis.

CU+LLLT decreases $\mathrm{Bax} / \mathrm{Bcl} 2$ ratio and rescue a decrease the formation of autophagosome induced by 6-OHDA in the cellular model of Parkinson's disease.

\section{Ethical Considerations}

This study was approved by the ethics committee of Shahid Beheshti University of Medical Sciences (IR. SBMU.RETECH.REC.1399.127).

\section{Conflict of Interests}

The authors declare no conflict of interest.

\section{Acknowledgment}

We are thankful for the funding provided by, Laser Application in Medical Sciences Research Center Shahid Beheshti University of Medical Sciences, Tehran, Iran (Grant number\#22116).

\section{References}

1. Chao Y, Wong SC, Tan EK. Evidence of inflammatory system involvement in Parkinson's disease. Biomed Res Int. 2014;2014:308654. doi: 10.1155/2014/308654.
2. Ebrahimi-Fakhari D, Wahlster L, McLean PJ. Protein degradation pathways in Parkinson's disease: curse or blessing. Acta Neuropathol. 2012;124(2):153-72. doi: 10.1007/s00401-012-1004-6.

3. Niknazar S, Nahavandi A, Peyvandi AA, Peyvandi $H$, Roozbahany NA, Abbaszadeh HA. Hippocampal NR3C1 DNA methylation can mediate part of preconception paternal stress effects in rat offspring. Behav Brain Res. 2017;324:71-6. doi: 10.1016/j.bbr.2017.02.014.

4. Dias V, Junn E, Mouradian MM. The role of oxidative stress in Parkinson's disease. J Parkinsons Dis. 2013;3(4):461-91. doi: 10.3233/JPD-130230.

5. Li B, Xiao L, Wang ZY, Zheng PS. Knockdown of STIM1 inhibits 6-hydroxydopamine-induced oxidative stress through attenuating calcium-dependent ER stress and mitochondrial dysfunction in undifferentiated PC12 cells. Free Radic Res. 2014;48(7):758-68. doi: 10.3109/10715762.2014.905687.

6. Wang YH, Xuan ZH, Tian S, Du GH. Echinacoside protects against 6-Hydroxydopamine-induced mitochondrial dysfunction and inflammatory responses in PC12 cells via reducing ROS production. Evid Based Complement Alternat Med. 2015;2015:189239. doi: 10.1155/2015/189239.

7. Joe B, Vijaykumar M, Lokesh BR. Biological properties of curcumin-cellular and molecular mechanisms of action. Crit Rev Food Sci Nutr. 2004;44(2):97-111. doi: 10.1080/10408690490424702.

8. Goel A, Kunnumakkara AB, Aggarwal BB. Curcumin as "Curecumin": from kitchen to clinic. Biochem Pharmacol. 2008;75(4):787-809. doi: 10.1016/j.bcp.2007.08.016.

9. Menon VP, Sudheer AR. Antioxidant and antiinflammatory properties of curcumin. Adv Exp Med Biol. 2007;595:105-125. doi: 10.1007/978-0-387-46401-5_3.

10. Alexander JA, Castillo M, Hoffman JC Jr. Magnetic resonance findings in a patient with internuclear ophthalmoplegia. Neuroradiological-clinical correlation. J Clin Neuroophthalmol. 1991;11(1):58-61.

11. Kowluru RA, Kanwar M. Effects of curcumin on retinal oxidative stress and inflammation in diabetes. Nutr Metab (Lond) 2007;4:8. doi: 10.1186/1743-7075-4-8.

12. Chan WH, Wu HJ, Hsuuw YD. Curcumin inhibits ROS formation and apoptosis in methylglyoxal-treated human hepatoma G2 cells. Ann N Y Acad Sci. 2005;1042:372-378. doi: 10.1196/annals.1338.057.

13. Mohsenifar Z, Fridoni M, Ghatrehsamani M, Abdollahifar MA, Abbaszadeh H, Mostafavinia A, et al. Evaluation of the effects of pulsed wave LLLTT on tibial diaphysis in two rat models of experimental osteoporosis, as examined by stereological and real-time PCR gene expression analyses. Lasers Med Sci. 2016;31(4):721-32. doi: 10.1007/s10103016-1916-9.

14. Fallahnezhad S, Piryaei A, Darbandi H, Amini A, Ghoreishi SK, Jalalifirouzkouhi R, et al. Effect of lowlevel laser therapy and oxytocin on osteoporotic bone marrow-derived mesenchymal stem cells. J Cell Biochem. 2018;119(1):983-97. doi: 10.1002/jcb.26265.

15. Darabi SH, Tiraihi T, Noori-Zadeh A, Rajaei F, Darabi L, Abbaszadeh HA. Creatine and retinoic acid effects on the induction of autophagy and differentiation of adipose tissue-derived stem cells into GABAergic-like neurons. J 
Babol Univ Med Sci. 2017;19(8):41-9.

16. Awasthi S, Pandya U, Singhal SS, Lin JT, Thiviyanathan V, Seifert WE Jr, et al. Curcumin-glutathione interactions and the role of human glutathione S-transferase P1-1. Chem Biol Interact. 2000;128(1):19-38. doi: 10.1016/s00092797(00)00185-x.

17. Chen J, Tang XQ, Zhi JL, Cui Y, Yu HM, Tang EH, et al. Curcumin protects PC12 cells against 1-methyl4-phenylpyridinium ion-induced apoptosis by bcl2-mitochondria-ROS-iNOS pathway. Apoptosis. 2006;11(6):943-53.

18. Chang CH, Chen HX, Yü G, Peng CC, Peng RY. Curcuminprotected PC12 cells against glutamate-induced oxidative toxicity. Food Technol Biotechnol. 2014;52(4):468-78. doi: $10.17113 / \mathrm{ftb} .52 .04 .14 .3622$

19. Uttara B, Singh AV, Zamboni P, Mahajan RT. Oxidative stress and neurodegenerative diseases: a review of upstream and downstream antioxidant therapeutic options. Curr Neuropharmacol. 2009; 7(1):65-74. doi: 10.2174/157015909787602823

20. Kim KM, Pae HO, Zhung M, Ha HY, Ha YA, Chai KY, et al. Involvement of anti-inflammatory heme oxygenase- 1 in the inhibitory effect of curcumin on the expression of proinflammatory inducible nitric oxide synthase in RAW264.7 macrophages. Biomed Pharmacother. 2008;62(9):630-6. doi: 10.1016/j.biopha.2008.01.008.

21. Abramova NA, Cassarino DS, Khan SM, Painter TW, and Bennett JP Jr. Inhibition by $\mathrm{R}(+)$ or S(-) pramipexole of caspase activation and cell death induced by methylpyridinium ion or beta amyloid peptide in SH-SY5Y neuroblastoma. J Neurosci Res. 2002;67(4):494-500. doi: 10.1002/jnr.10127.

22. Tang XQ, Feng JQ, Chen J, Chen PX, Zhi JL, Cui Y, et al. Protection of oxidative preconditioning against apoptosis induced by $\mathrm{H} 2 \mathrm{O} 2$ in PC12 cells: mechanisms via MMP, ROS, and Bcl-2. Brain Res. 2005.1057(1-2):57-64. doi: 10.1016/j.brainres.2005.07.072.

23. Ghorabi MT, Aliaghaei A, Sadeghi Y, Shaerzadeh F, Rad AA, Mohamadi R, et al. Evidence supporting the neuroprotective effect of adipose derived stem cells on PC12 cells against oxidative stress induced by $\mathrm{H} 2 \mathrm{O} 2$. Cell Mol Biol (Noisy-le-grand). 2017;63(3):1-6. doi: 10.14715/ $\mathrm{cmb} / 2017.63 .3 .1$.

24. Clementi ME, Pani G, Sampaolese B, Tringali G. Punicalagin reduces $\mathrm{H} 2 \mathrm{O} 2$-induced cytotoxicity and apoptosis in PC12 cells by modulating the levels of reactive oxygen species. Nutr Neurosci. 2018;21(6):447-454. doi: 10.1080/1028415X.2017.1306935. 